\title{
A Simulation Study on Production Logistics Balance Based on Petri Net + Flexsim
}

\author{
Zhiwang Qian $^{1, \text { a }}$, Haitao Sun ${ }^{2, \text { b }}$ \\ ${ }^{1}$ University of Shanghai for Science \& Technology, Shanghai ,200093,China \\ 2 Shanghai Medical Instrumentation College, Shanghai ,200093,China \\ aemail:qzhwang@126.com, bemail:sunht@smic.edu.cn
}

Keywords: Petri net; Flexsim; Production logistics balance

\begin{abstract}
The manufacturers' quick response to their market demand largely depends on whether their production logistics system is in a balance and coordination status. A simulation experiment of production logistics balance is conducted for a manufacturing enterprise in the process of processing production, using Petri net + Flexsim software in this paper, which analyses the features and effects of the production logistics system, eventually comes up with some improvement strategies and optimizations addressing the identified bottleneck problems.
\end{abstract}

\section{Introduction}

Production logistics system is a kind of the complex discrete event system with high degree of randomness. In the stage of system designing, it is more difficult to figure out the coordination of the system as a whole and the capability collocation of all sorts of equipment by using traditional calculation and estimation. However, computer simulation technology makes it possible to conduct simulation experiment of system model, analyze the characteristics and effects of a designing, an existing or a running system to see if it is in a balance or coordination state for the purpose of coming up with improvement idea. Currently, there are a lot of software in modeling and simulation of production logistics system, such as Petri net, AutoMod, RaLC, Witness, eM-Plant and Matlab. Compared with the other modeling tools, Petri net is mathematical expression for discrete parallel system, the model of which is not only a good indicator of logical relations of system, but also can introduce time factor that describes the real-time dynamic process and statistics of production system. Therefore, it is widely used in designing, analysis and simulation of production system. But, this method is dependent on specific flow description language, and somehow is limited in practice. On the contrary, Flecsim is abundant in object model library, as a visible modeling tool, features powerful simulation and analysis, so it effectively avoids the defects of Petri net. The combination is capable of describing the internal information flow of production system and internal material flow as well. Therefore, the integration of Petri net + Flexsim software is adopted to conduct the simulation study on logistics balance in the paper, which seeks the existing bottlenecks in production to ensure the production logistics balance with new improvement measures.

\section{Petri Net Basics}

\subsection{Definition}

\section{Definition 1}

The basic Petri is a directed graph composed of 5 elements: $\mathrm{PN}=(\mathrm{P}, \mathrm{T}, \mathrm{I}, \mathrm{O} \mathrm{m})$

Where

(1) $\mathrm{p}=\left\{\mathrm{p}_{1}, \mathrm{p}_{2}, \bullet \bullet, \mathrm{p}_{\mathrm{n}}\right\}$ is finite set of the places, $\mathrm{n}>0$ where $\mathrm{n}$ is the number of places;

(2) $T=\left\{\mathrm{t}_{1}, \mathrm{t}_{2}, \cdots, \mathrm{t}_{\mathrm{m}}\right\}$ is finite set of transition, $\mathrm{m}>0$

(3) $I: P \times T \rightarrow N$ is input function, which defines the number of replications or the set of weights directed connection from T to $\mathrm{P}$, where $N=\{0,1, \bullet \bullet\}$ is nonnegative positive integer; 
(4) $O: T \times P \rightarrow N$ is output function, which defines the number of replications or the set of weights directed connection from $\mathrm{T}$ to $\mathrm{P}$;

(5) $\mathrm{m}: P \rightarrow N$ is identifier for Petri, as a column vector, where the ith element stands for the number of tokens in the ith place, $\mathrm{m}_{0}$ is the original identifier for the initial state. The number of tokens in place $\mathrm{P}$ is represented by $\mathrm{m}_{\mathrm{p}}$.

(6) $P \cap T=\varnothing$ (for place and transition as the 2 sorts of different elements), also $\mathrm{P} \cup \mathrm{T}=\varnothing$ (for 1 element at least in the net);

where " $X$ " is Cartesian product. If $I(\mathrm{p}, \mathrm{t})=\mathrm{w}$ is for the value of output function from place $\mathrm{P}$ to transition $\mathrm{T}$, and $O(\mathrm{p}, \mathrm{t})=\mathrm{w}$ for the value of in put function from place $\mathrm{P}$ to transition $\mathrm{T}$, moreover, $\mathrm{w}$ is nonnegative positive integer, therefore, $\mathrm{I}$ and $\mathrm{O}$ all can be $\mathrm{n} \times \mathrm{m}$ matrix of nonnegative positive integer, the difference $C=O-I$ is named as incidence matrix.

Generally speaking, ${ }^{\bullet t}$ is for the set of all the input places of transition $t,|\bullet t|$ for the number of input places of $t$; $t$ - for the set of all the output places of transition $t,|t \bullet|$ for the number of output places of $\mathrm{t}$; $\bullet \mathrm{P}$ for the set of the input transition of $\mathrm{P}$; $\mathrm{p} \cdot$ for the set of the output transition of $\mathrm{P}$, $|\bullet p|$ for the number of input transition $t ;|\mathrm{p} \bullet|$ is for the number of all the output transitions of place $\mathrm{p}$.

Definition 2:

Transition $\mathrm{t} \in T$ can be triggered by the identifier $\mathrm{m}$, and only: $\forall \mathrm{p} \in \bullet \cdot \mathrm{t}: \mathrm{m}(\mathrm{p}) \geq \mathrm{I}(\mathrm{p}, \mathrm{t})$. - $t$ is for the set of output places of $t$. The trigger of transition $t$ is to decrease considerable tokens from gt, meanwhile increasing considerable tokens, so that makes the identifier of Petri net change, which meets the rules as follows:

The trigger of transition $\mathrm{t}$ by the identifier $\mathrm{m}$ produces new one $\mathrm{m}^{\prime}$, for $\forall \mathrm{p} \in P$ :

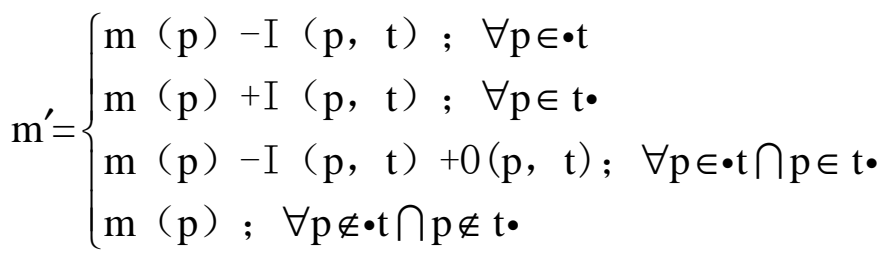

Table 1 Workshop Configuration (Unit: piece)

\begin{tabular}{|c|c|c|c|c|c|}
\hline & Ordinary & Drilling & Milling & Grinding & Testing \\
\hline Machines & 3 & 3 & 2 & 3 & 1 \\
\hline
\end{tabular}

Identifier $\mathrm{m}^{\prime}$ can be reached from $\mathrm{m}$ by the trigger $\mathrm{t}$, marked as: $\left.\mathrm{m} \backslash \mathrm{t}\right\rangle \mathrm{m}^{\prime}$ 。

\subsection{Representation method of Petri net model}

Petri net is a directed graph, the structure elements of which are listed below.

(1) Place is expressed by a circle " $\mathrm{O}$ " in the graph describing the possible internal status of system, such as model input, output variables or model state.

(2) Transition is labeled by a thick short line “|”, a filled rectangle “ $\boldsymbol{\square}$ ” or an outlined rectangle “ $\square$ ”, describing changing time of system state. In case of output of the existing condition, it may also describe restriction condition.

(3) Directed arc is for connection between place and transition. Directed arc fulfills the transition of internal state occurred by events, with different elements from beginning to end. The arc line represents the connection of transitions to places in the modeling system.

(4) Token is labeled by black point in the graph, which represents source or number of conditions.

(5) Mark is considered to be a symbol to see whether the value of variables present or not.

Place: $\mathrm{P}=\{\mathrm{p} 1, \mathrm{p} 2, \mathrm{p} 3\} \quad$ Transition: $\mathrm{T}=\{\mathrm{t} 1, \mathrm{t} 2, \mathrm{t} 3\}$

Input function: $I(p 1, t)=1, I(p 1, t 2)=0, I(p 1, t 3)=0 ; I(p 2, t 1)=0, I(p 2, t 2)=1, I(p 3, t 3)$

$=0 ; \mathrm{I}(\mathrm{p} 3, \mathrm{t} 1)=0, \mathrm{I}(\mathrm{p} 3, \mathrm{t} 2)=0, \mathrm{I}(\mathrm{p} 3, \mathrm{t} 3)=1$;

Output function: $\mathrm{O}(\mathrm{p} 1, \mathrm{t} 1)=0, \mathrm{O}(\mathrm{p} 1, \mathrm{t} 2)=0, \mathrm{O}(\mathrm{p} 1, \mathrm{t} 3)=1 ; \mathrm{O}(\mathrm{p} 2, \mathrm{t} 1)=1, \mathrm{O}(\mathrm{p} 2, \mathrm{t} 2)=0$, 
$\mathrm{O}(\mathrm{p} 2, \mathrm{t} 3)=0 ; \quad \mathrm{O}(\mathrm{p} 3, \mathrm{t} 1)=0, \mathrm{O}(\mathrm{p} 3, \mathrm{t} 2)$

$=1$, $\mathrm{O}(\mathrm{p} 3, \mathrm{t} 3)=0$;

Initial state: $\mathrm{m}_{0}=(1,0,0)^{\mathrm{T}}$

Input function: $I=\left(\begin{array}{lll}1 & 0 & 0 \\ 0 & 1 & 0 \\ 0 & 0 & 1\end{array}\right)$

Output function: $O=\left(\begin{array}{ccc}0 & 0 & 1 \\ 1 & 0 & 0 \\ 0 & 1 & 0\end{array}\right)$

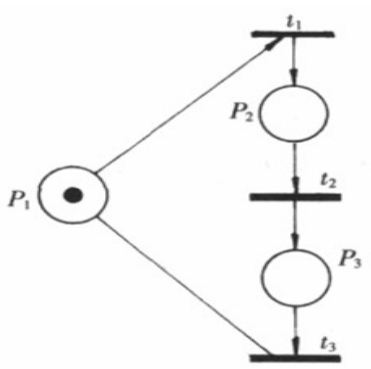

Graph 1. Descriptive Graph of Formalization of Marked PN.

Incidence matrix: $\quad C=O-I=\left(\begin{array}{ccc}-1 & 0 & 1 \\ 1 & -1 & 0 \\ 0 & 1 & -1\end{array}\right)$

Table 2 Process Time (Unit: $\min$ )

\begin{tabular}{|c|c|c|c|c|c|}
\hline Item Type & Ordinary & Drilling & Milling & Grinding & Testing \\
\hline 1 & 5 & 5 & 4 & 4 & 6 \\
\hline 2 & 4 & 4 & 3 & 4 & 3 \\
\hline 3 & 4 & 5 & 3 & 4 & 1 \\
\hline
\end{tabular}

\section{Introduction to Flexsim Simulation Software}

Flexsim, as commercialized software, is the most powerful tool for modeling, analyzing, visualizing in 3D, and optimizing any imaginable process - from manufacturing to supply chains, abstract examples to real world systems, and anything in between.

\section{Simulation Case Study}

\subsection{Simulation task}

A production enterprise is composed of such 5 workshops as general, drilling, milling, grinding machine and testing workshop to process 3 types of items. The production line of these workshops is a hybrid flow with features that many kinds of products can be produced in a mixed style at the same time. According to the fixed hybrid product groups, namely, different products are numbered into product groups based on their fixed portion and sequence, and then are manufactured on the assembly line group by group. The production logistics system of the hybrid assembly line is quite capable of its flexibility, which can quickly change production plan on the basis of demand change, and largely accelerate the enterprise's quick response and adaptability to the external demand change.

Some details about the number of lathes, process time and output in the enterprise are shown in the following table 1, 2 and 3.

\begin{tabular}{|c|c|c|c|}
\hline \multicolumn{5}{|c}{ Table3 Product Output (Unit: piece) } \\
\hline Item Type & Total & Batch & Time interval \\
\hline 1 & 1000 & 10 & 3 \\
\hline 2 & 500 & 5 & 3 \\
\hline 3 & 200 & 2 & 3 \\
\hline
\end{tabular}

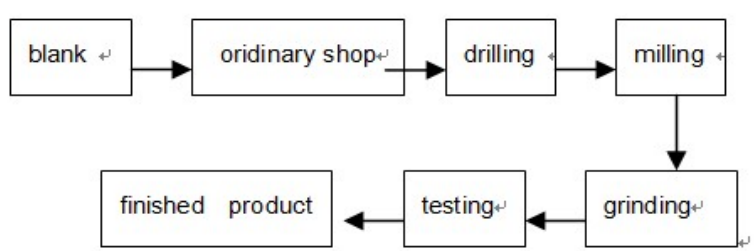

Graph2 Conceptual Model

Other system parameters:

(1) capacity of working storage area is1700.

(2) transmission speed of conveyor is $1 \mathrm{~m} / \mathrm{s}$

(3) if setting 1700 pieces products are done, source would automatically stop working.

The conceptual model of product process is shown in the graph2.

The question is how to conduct a simulation analysis on logistics balance in this production, and judge whether or not the logistics imbalance exists in the production logistics system; what measures should be taken to optimize the system. 


\subsection{Simulation process and analysis}

Firstly, it is needed to build Petri net model in production, shown in graph3.

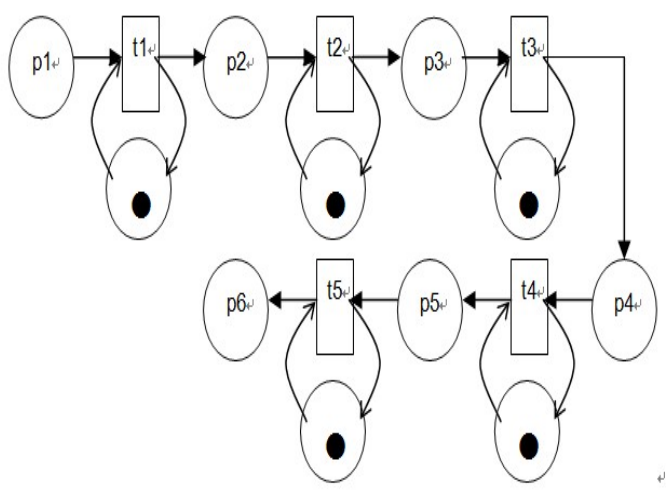

Graph3 Petri net model of single product .
Table4 Notes to the symbols

\begin{tabular}{|l|l|}
\hline $\mathrm{p} 1$ :workpiece amival & $\mathrm{p} 2$ : finished by ordinary tool \\
\hline $\mathrm{p} 3$ :finished by drilling tool & $\mathrm{p} 4$ : finished by milling tool \\
\hline $\mathrm{p} 5$ : finished by grinding tool & $\mathrm{p} 6$ : testing is done for output \\
\hline $\mathrm{t} 1$ :processed by ordinary tool & $\mathrm{t} 2$ : processed by drilling tool \\
\hline $\mathrm{t} 3$ : processed by milling tool & $\mathrm{t} 4$ : processed by ginding tool \\
\hline $\mathrm{t}$ : : testing & $\begin{array}{l}\text { Black point: token (can be } \\
\text { used by machine) }\end{array}$ \\
\hline
\end{tabular}

Secondly, transforming Petri net model into physical model in Flexsim, shown in graph4.

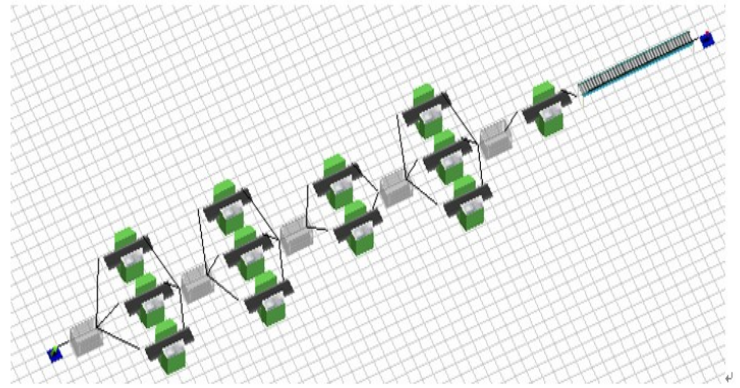

Graph4 Physical Model in Flexsim.

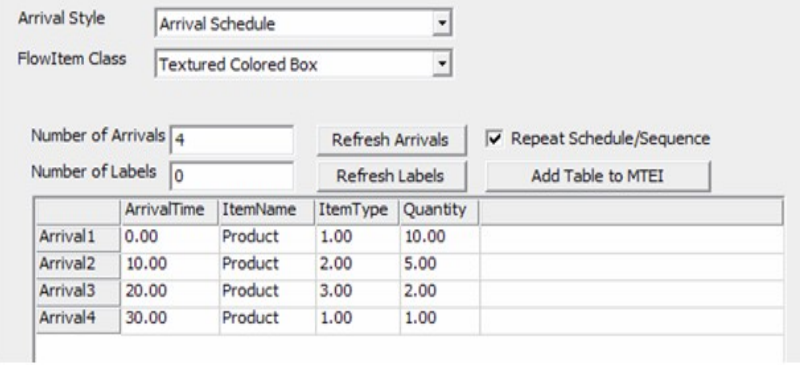

Graph5 Parameter Setting in Source

The other important parameters in the model are shown in grapy5 and 6.

Adding sentence into code editor window of conveyor: if (getoutput (current) ==1699) stop

( ) ; If setting 1700 pieces are sent, model would stop simulating, shown in graph7.

Thirdly, after setting all the parameters, click the compile button in the main window, and start automatically compiling. When compiling is done, click the reset button in the main window, have all the model parameters return to their initial state, then click run button to run the model.

The total running time of the model lasts 7728 minutes, the main parameter report produced in simulation is shown in table5.

P Processor8 - Process Tine Tenplate
Process Time is defined by cases referenced by itemtype
camber:
case 1: return 4;
case 2: return 3;
case 3: return 4;
default: return 3;
Notes:
Case instances must be a valid itemtype number.
Additional cases may be added as needed.
I lea "nurrant" tn snnoce tho nurrant nhiont

Graph6 Milling Parameter Setting

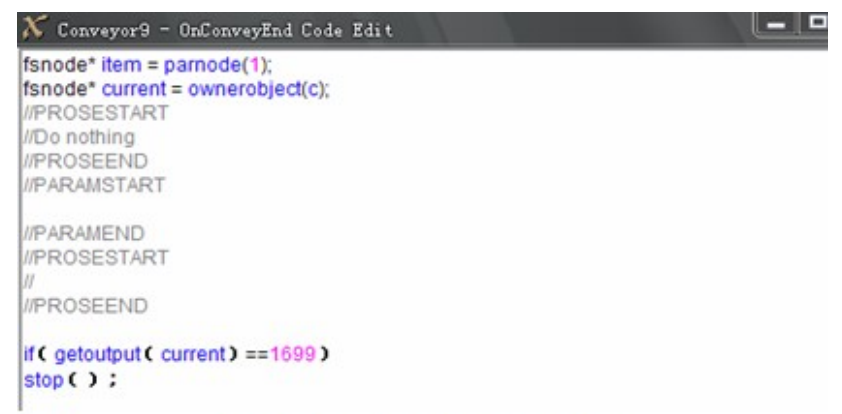

Graph7 Parameter Setting of Conveyor

Lastly, analysis is on the simulation outcome. From table5 it can be seen that the enterprise fails to achieve balance production, with imbalance production line and uneven busy idle situation, also with bigger inventory, logger cycle time and higher cost. Specifically, the average residence time for WIP product in milling shop accounts for 28.558235 minutes, which means the two milling machines are so incapable of processing the products that there is backlog of WIP flowing from last workshop. Consequently, it leads to WIP inventory that affects next process with overlong average wait time of 797 minutes in grinding workshop. As the first bottleneck in the enterprise's production line, it seriously wastes resources, increasing cost. In testing workshop, it takes longer 
time to wait, averagely for 2331.06 minutes, thus the production cycle time is prolonged. It tells that it falls far short of demand to configure just 1 machine in testing. The danger is that the finished products may be obsolete when they get to the customers due to the reduced responsiveness to the market demand.

\subsection{Improvement measures}

As above-mentioned situation, we come up with the following measure.

First, redefining manufacturing sequence. Defining manufacturing sequence aims to achieve the production equalization. Different product has different process time in each process stage. To rationalize the production sequence can coordinate and balance running time in different process stage to avoid busy idle occurrences, making production equipment in a full load state. Accounting backward technique in production can be adopted to identify production sequence based on the 3 item types of 1000,500,200 respectively, so the sequence can be calculated as 12121321213211111.

Secondly, adding more relative equipment. According to the average residence time of 28.558235 minutes in the milling workshop it is needed to install 1 milling tool. Then another $3-4$ testing machines should be added to curtail the longer wait time in testing stage.

Thirdly, setting buffer link. Two time buffers should be set between time of completion in ordinary shop and start time in drilling shop, and between the later two process steps respectively.

Fourthly, curtailing running time in grinding machine. Longer idle time of grinding tool means a shortage of milling capacity, which leads to longer WIP wait time affecting the production in milling step. On the other hand, there is excess capacity of milling tools that need rest for 1 or 2 hours rather than continuously working.

\section{Summary}

The production logistics system in a enterprise is

Table5 Data Report in Simulation (Unit: min)

\begin{tabular}{|c|c|c|c|c|}
\hline Item & $\begin{array}{c}\text { Average residence } \\
\text { time }\end{array}$ & Idle time & Work time & Wait time \\
\hline source & 0 & 0 & 0 & 7720 \\
\hline $\begin{array}{c}\text { Ordinary } \\
\text { shop } \\
\text { machine 1 }\end{array}$ & 6.117647 & 0 & 0 & 0 \\
\hline machine 2 & 4.5 & 297 & 2700 & 0 \\
\hline machine 3 & 4.5 & 297 & 2700 & 0 \\
\hline Drilling time & 4.411765 & 594 & 2400 & 0 \\
\hline machine 1 & 4.666667 & 0 & 0 & 0 \\
\hline machine 2 & 4.666667 & 203 & 2800 & 0 \\
\hline machine 3 & 4.8 & 203 & 2800 & 0 \\
Milling shop & 28.558235 & 599 & 2400 & 0 \\
machine 1 & 3.58235 & 0 & 0 & 0 \\
machine 2 & 3.58235 & 10 & 3050 & 0 \\
Grinding & 0 & 11 & 3050 & 0 \\
shop & 4 & 0 & 0 & 0 \\
\hline machine 1 & 4 & 796 & 2268 & 0 \\
\hline machine 2 & 4 & 797 & 2268 & 0 \\
machine 3 & 4 & 798 & 2264 & 0 \\
Testing shop & 2331.059412 & 0 & 0 & 0 \\
machine 1 & 4.529412 & 18 & 7700 & 0 \\
conveyor & 10 & 0 & 0 & 0 \\
sink & 0 & 0 & 0 & 0 \\
\hline
\end{tabular}
modeled by using Petri net + Flexsim software in this paper, which studies the bottlenecks in the system through simulation experiment and analysis. Eventually, some improvement strategies and optimizations have come up with. The defects are short of optimization modeling addressing the identified bottleneck problems.

\section{References}

[1]Chongyi Yuan. The Principle of Petri Net [M]. Publishing House of Electronics Industry, Beijing, 1998: $18 \sim 20$.

[2]Zhehui Wu. Introduction to Petri Net [M]. China Machine Press ， Beijing, 2006: 133.

[3]Averill M. Law, W. David Kelton. Simulation Modeling and Analysis (English Reprint 
Edition,3rd Edi. ) [M]. Tsinghua University Press, Beijing, 2004.

[4]Eamonn Lavery, Ph.D., Bill Nordgren, Cliff King, Roger Hullinger. Flexsim Modeling Environment [J].System Simulation and Scientific Computing, 2005 (10) : 24 27.

[5]Zhiwang Qian. System Construction and Simulation of Flexible Production Enterprise Logistics [M], China Morden Economics Publishing House, Beijing, 2009: 173 181 . 